\title{
Deformation induced by wetting: a simple model
}

\author{
Francesca Casini
}

\begin{abstract}
This paper presents a simple model for predicting the deformation induced by wetting. The objective is to quantify the deformation induced by saturation of an unsaturated layer of homogeneous soil, causing variation of the initial void ratio and gravimetric water content. The soil is a low-plasticity silty sand. A simple expression for the normal compression line (NCL), which depends on the parameter $\chi$ and one more parameter, will be proposed. The model may capture the progressive degradation induced by loading and wetting by linking the dependency of NCL by the parameter $\chi$ and water retention curve by porosity.
\end{abstract}

Key words: constitutive relations, laboratory tests, partial saturation, deformation, water retention curve.

Résumé : Cet article présente un modèle simple pour la prédiction de la déformation induite par le mouillage. L'objectif est de quantifier la déformation induite par la saturation d'une couche de sol homogène non saturée, causant ainsi des variations de l'indice des vides initial et de la teneur en eau gravimétrique initiale. Le sol est un sable silteux à faible plasticité. Une expression simple de la ligne de compression normale ( $\mathrm{LCN})$, qui dépend du paramètre $\chi$ et d'un autre paramètre, est proposée. Le modèle permet d'intégrer la dégradation progressive causée par le chargement et le mouillage, en reliant la dépendance de la LCN avec le paramètre $\chi$ et la courbe de rétention d'eau avec la porosité.

Mots-clés : relations constitutives, essais en laboratoire, saturation partielle, déformation, courbe de rétention d'eau.

[Traduit par la Rédaction]

\section{Introduction}

The prediction of settlement induced by wetting is of particular importance in ground engineering. To mitigate sudden displacement during the life of a structure or of a natural deposit, it is important to predict the deformation of soils induced by the wetting process as unsaturated soils may either swell or shrink when they experience a wetting path. This is a function of the initial conditions in terms of void ratio and water content (e.g., from experimental investigations: Lawton et al. 1989; Gens et al. 1995; Ferber et al. 2008; Muñoz-Castelblanco et al. 2011; Vilar and Rodrigues 2011; also from theoretical point of view: Alonso et al. 1990; Or 1996; Lu et al. 2010).

The Barcelona basic model, developed by Alonso et al. (1990), was the first to capture certain features of unsaturated soil behaviour. In the last three decades, many constitutive models have been proposed to also achieve this (e.g., Jommi and di Prisco 1994; Alonso et al. 1999; Gallipoli et al. 2003a; Tamagnini 2004; Sun et al. 2008; Alonso et al. 2010; Mašín 2010). This modern trend highlights the importance of taking the dual dependency of mechanical behaviour and retention properties into account. In particular, a lot of work has been done in the last decade on the dependency of the water retention curve on the void ratio (Romero and Vaunat 2000; Gallipoli et al. 2003b; Nuth and Laloui 2008; Tarantino 2009; Romero et al. 2011; Casini et al. 2012).

This paper presents a simple model to evaluate the deformation induced by wetting (under oedometric conditions) knowing the saturated normal compression line (NCL) and adopting one more parameter for quantifying the rate of change of effective stress caused by variation of parameter $\chi$. As pointed out by Gens et al. 2006, the constitutive models of unsaturated soils are classified in three different classes depending on the definition of parameter $\chi$ : class $1 \chi=0$ (e.g., Alonso et al. 1990) net stresses formulation; class $2 \chi=$ $\chi(s)$ depending on suction $(s)$ but not of the amount of the water in the soil $\left(V_{\mathrm{w}}\right)$ (e.g., Khalili et al. 2004); class $3 \chi=$ $\chi\left(V_{\mathrm{w}}, s\right)$ (e.g., Jommi 2000) depending on suction and the amount of water in the soil. The class 3 model is adopted because of its conceptual advantages as the straightforward transition between saturated and unsaturated states and the direct incorporation of the hydraulic hysteresis.

The parameter $\chi$, in the class 3 model, is related to the degree of saturation, different kind of expression has been recently proposed: $\chi=\left(S_{\mathrm{r}}-S_{\text {rres }}\right) /\left(S_{\text {rsat }}-S_{\text {rres }}\right)$ (e.g., Lu et al. $2010) ; \chi=\left(S_{\mathrm{r}}-S_{\text {r_micro }}\right) /\left(S_{\text {rsat }}-S_{r_{\text {r micro }}}\right), \chi=\left(S_{\mathrm{r}}\right)^{\alpha}$, where $S_{\mathrm{r} \_ \text {micro }}$ is the microscopic degree of sauration and $\alpha$ is a material parameter (e.g., Alonso et al. 2010). As a simplification, the parameter $\chi$ is considered equal to the degree of saturation $S_{\mathrm{r}}$, because the contribution of term $S_{\mathrm{r}} s$ give error prediction for high value of suction $(\geq 1 \mathrm{MPa})$ typical of clayey soils, however in this work the attention is focused on the behaviour of a silty sand. Any different expression for $\chi=\chi\left(S_{\mathrm{r}}\right)$, can be easily adopted in the simple model proposed.

Many authors have already proposed the NCL equations of unsaturated soils that are dependent on the variation of $S_{\mathrm{r}}$, such as Al-Badran and Schanz (2010), Zhang and Ikariya (2011), and Kikumoto et al. (2011). The models previously

Received 6 September 2011. Accepted 31 May 2012. Published at www.nrcresearchpress.com/cgj on 24 July 2012.

F. Casini. Institute for Geotechnical Engineering, Swiss Federal Institute of Technology (ETHZ), Zurich, Switzerland.

E-mail for correspondence: francesca.casini@upc.edu. 
mentioned relate the shift of the NCL to the parameter introduced ad hoc in the formulation, while the shift proposed in this paper is derived consistently from the variation of the preconsolidation pressure with the degree of saturation.

From an engineering perspective, the objective is to provide a simple way to predict the deformation induced by wetting as a result of rainfall, for example, infiltration known as the NCL in saturated condition, the slope of the unloadingreloading line, the degree of saturation, and one additional parameter.

\section{Material and test procedures}

The soil is a low-plasticity silty sand from a steep slope in Rüdlingen, in northeast Switzerland, where a triggering experiment was carried out in March 2009 (Springman et al. 2009; Casini et al. 2010; Askarinejad et al. 2012).

The samples were statically compacted at the target water content and void ratio. Loose soil was initially mixed to a target water content. By assuming that the water content of the wet mixture was equal to the target value, an appropriate mass of soil was compacted in one layer by one-dimensional static compression to achieve the target dry unit weight.

The water retention curve (WRC) was obtained using a Fredlund apparatus (Perez Garcia et al. 2008) under suctioncontrolled conditions for three statically compacted (diameter, $D=6.3 \mathrm{~cm}$; height, $H=2 \mathrm{~cm}$ ) samples with an initial void ratio $e_{0}$ of $0.58,0.85$, and 1.1 , respectively, and initial gravimetric water content $w_{0}=15 \%$. The results of the wetting path are reported in Fig. 1 in terms of degree of saturation $S_{\mathrm{r}}=V_{\mathrm{w}} / V_{\mathrm{v}}$, where $V_{\mathrm{w}}$ and $V_{\mathrm{v}}$ are the volume of water and voids, respectively, and suction $s=u_{\mathrm{a}}-u_{\mathrm{w}}$, where $u_{\mathrm{a}}$ and $u_{\mathrm{w}}$ are the pore air and water pressures, respectively. The results show that, as the void ratio decreases, the water retained by the soil increases. For a suction $s=10 \mathrm{kPa}, S_{\mathrm{r}}$ ranges between $0.35,0.50$, and 0.75 as the void ratio decreases from 1.10 to 0.58 .

The oedometer samples $(7 \mathrm{~cm}$ in diameter) were compacted in one layer to a height of $2 \mathrm{~cm}$. Four oedometer tests were performed up to $\sigma_{\mathrm{v}}=400 \mathrm{kPa}$ on compacted samples prepared with $w=14.3 \%-23 \%$ also including unloading-reloading path for $\sigma_{\mathrm{v}}=200 \mathrm{kPa}$ as shown in Fig. $2 a$ in terms of vertical stress, $\sigma_{\mathrm{v}}$, and void ratio, $e$ Two samples were tested at initial constant water contents $w_{0}=14.3 \%-23 \%$, respectively, the others two samples were saturated and then tested (Habegger et al. 2011). As highlighted by the experimental data (Fig. 2a), the mechanical behaviour of the unsaturated samples can be regarded as a combination of the behaviour of the corresponding saturated soil and the structural effects induced by partial saturation. As the soil is loaded, the initial bonds due to the partial saturation are progressively damaged and the degree of saturation increases correspondingly with volume loss, while the behaviour of the unsaturated soils tends toward that of the saturated soil. The unloading-reloading paths are not affected by $S_{\mathrm{r}}$.

Six oedometer samples, compacted at a target water contents $w=15 \%$ and $20 \%$, respectively, were compressed up to a vertical stress $\sigma_{\mathrm{v}}$ of 100,200 , and $400 \mathrm{kPa}$. Then the samples at constant vertical stress were fully soaked. The vertical line in Figs. $2 b-2 c$ indicates the stress at which the samples were flooded and the change in void ratio induced by
Fig. 1. Water retention data on reconstituted samples of Rüdlingen silty sand at three different void ratios under $\sigma_{\mathrm{v}}-u_{\mathrm{a}}=5 \mathrm{kPa}$.

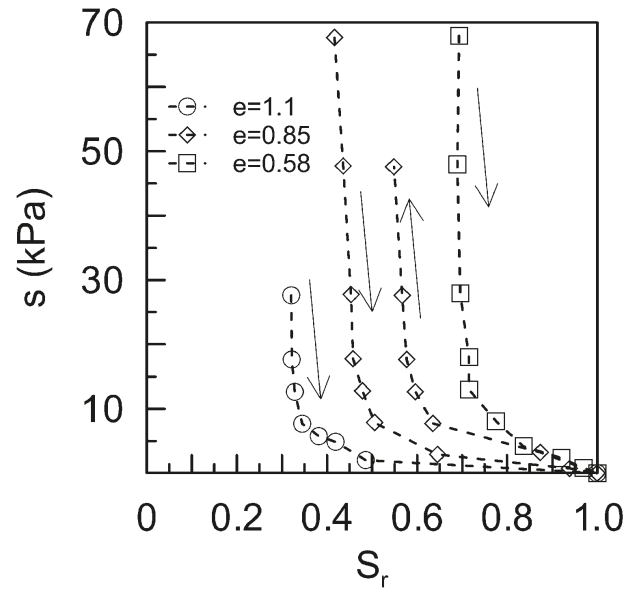

wetting in the plane $e-\log \sigma_{\mathrm{v}}$. For the same vertical stress, the position of the experimental points after saturation are similar to that of the samples saturated at the beginning of the test.

\section{Modelling framework}

Many constitutive models have been developed to describe the mechanical behaviour of unsaturated soils (e.g., Wheeler and Sivakumar 1995; Romero and Jommi 2008; Sheng et al. 2008; D'Onza et al. 2011; Zhang and Ikariya 2011). Suction was recognised early as the fundamental variable in the description of the unsaturated soil behaviour. However, a second variable is generally required to represent the stabilizing influence of suction on interparticle forces and the volumetric effects of its removal or weakening, by wetting (Gens et al. 2006).

The constitutive relationships for the mechanical behaviour are defined here in terms of Bishop's (Bishop 1959) stress $\sigma_{i j}^{\prime}=\sigma_{i j}-u_{\mathrm{a}} \delta_{i j}+\chi\left(u_{\mathrm{a}}-u_{\mathrm{w}}\right) \delta_{i j}$ and suction $s=u_{\mathrm{a}}-u_{\mathrm{w}}$, where $\sigma_{i j}$ is the total stress, $\chi$ is a weighting parameter, taking into account $S_{\mathrm{r}}$, and $\delta_{i j}$ is the Kronecker delta.

The vertical soil skeleton (effective) stress is defined as

[1] $\quad \sigma_{\mathrm{v}}^{\prime}=\sigma_{\mathrm{v}}-u_{\mathrm{a}}+\chi\left(u_{\mathrm{a}}-u_{\mathrm{w}}\right)$

In this work the evolution of the preconsolidation vertical stress $\sigma_{\mathrm{vc}}^{\prime}$ in unsaturated conditions is defined as the product of a term that is the function of the volumetric plastic strain $\left(\sigma_{\text {vcsat }}^{\prime}\right)$ and a term depending on $\chi$. Following Tamagnini (2004) the expression

$$
\text { [2] } \quad \sigma_{\mathrm{vc}}^{\prime}=\sigma_{\mathrm{vcsat}}^{\prime} \exp ^{\bar{a}(1-\chi)}
$$

$\bar{a}$ is adopted as a model parameter.

The change in preconsolidation effective stress is a combination of a reversible component related to change in $\chi$ and an irreversible component dependent on the development of plastic strains. The model predicts that a drying process induces some bonding (positive hardening) while a wetting process induces some debonding (negative hardening). 
Fig. 2. Oedometer compression curves on reconstituted samples of Rüdlingen silty sand: $(a)$ saturated and unsaturated samples up to $400 \mathrm{kPa} ;(b) w_{0}=15 \%$, and $(c) w_{0}=20 \%$ and then saturated at $\sigma_{\mathrm{v}}=100,200$, and $400 \mathrm{kPa}$.
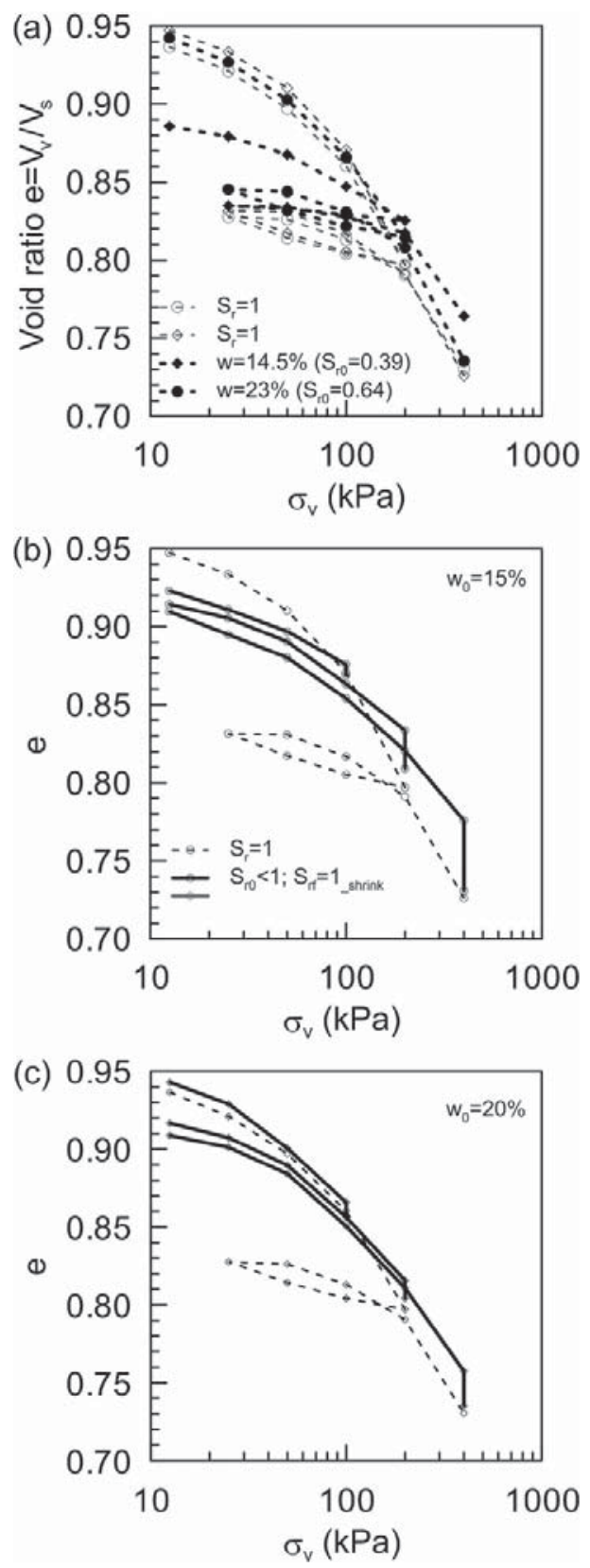

Table 1. Mechanical model parameters.

\begin{tabular}{llll}
\hline$B$ & $C_{\mathrm{c}}$ & $C_{\mathrm{s}}$ & $a$ \\
\hline 1.3 & 0.22 & 0.05 & 0.3 \\
\hline
\end{tabular}

Considering an oedometric compression test starting from a virgin state, in an analogy with saturated soils, the NCL is given by

[3] $e=B(\chi)-C_{\mathrm{c}} \log \sigma_{\mathrm{v}}^{\prime}$
Fig. 3. Stress path followed by a point $p$ to saturation $s$. Point i represents the saturated preconsolidation vertical stress of point $\mathrm{p}$. $\Delta e_{\text {sat }}$ is the variation of void ratio induced by saturation predicted by the model.

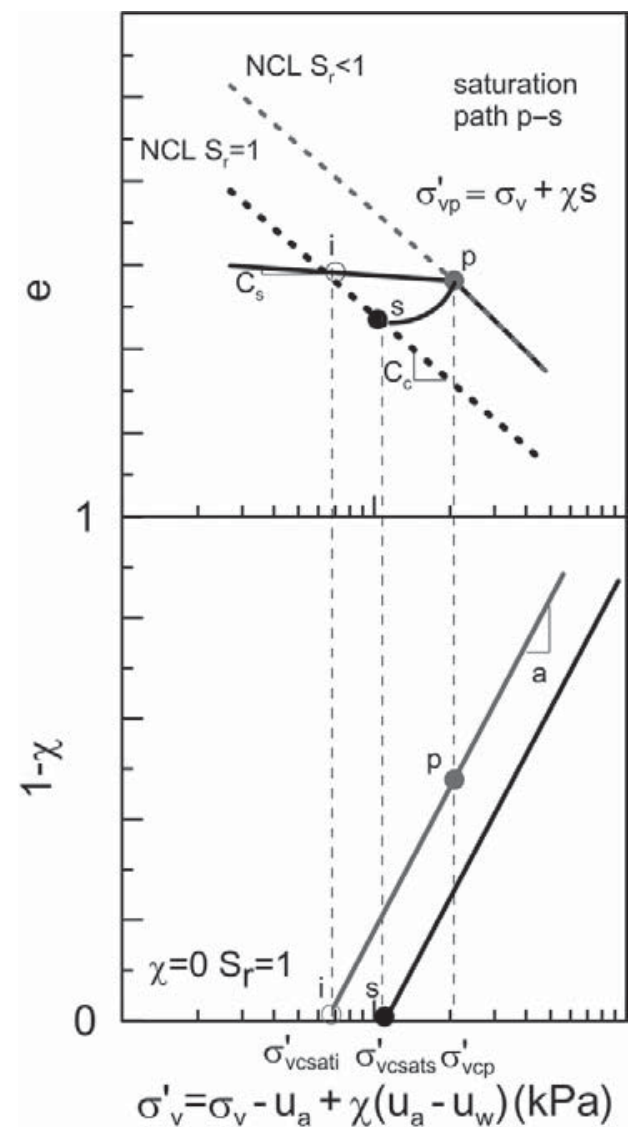

where $\sigma_{\mathrm{v}}^{\prime}$ is the vertical effective stress defined by eq. [1], $B$ $(\chi)$ is the void ratio at $1 \mathrm{kPa}$, and $C_{\mathrm{c}}$ is the compression index. The elastic change of void ratio $\Delta e^{\mathrm{e}}$ by

[4] $\Delta e^{\mathrm{e}}=-C_{\mathrm{s}} \log \sigma_{\mathrm{vf}}^{\prime} / \log \sigma_{\mathrm{v} 0}^{\prime}$

where $C_{\mathrm{s}}$ is the elastic swelling index and $\sigma_{\mathrm{v} 0}^{\prime}$ and $\sigma_{\mathrm{vf}}^{\prime}$ are the initial and final value of the vertical soil skeleton stress, respectively. The parameters for the mechanical model are reported in Table 1.

The dependency of $B(\chi)$ can be obtained easily from eq. [3] and from

$$
\text { [5] } e_{\mathrm{i}}=B-C_{\mathrm{c}} \log \sigma_{\mathrm{vcsa}}^{\prime}, \quad e_{\mathrm{i}}=e_{\mathrm{p}}-C_{\mathrm{s}} \log \frac{\sigma_{\mathrm{vcsat}}^{\prime}}{\sigma_{\mathrm{vc}}^{\prime}}
$$

where $e_{\mathrm{i}}$ and $e_{\mathrm{p}}$ are the void ratios in saturated and unsaturated conditions, respectively, on NCL (Fig. 3), $B$ is the void ratio at a vertical stress $\sigma_{\mathrm{v}}^{\prime}=1 \mathrm{kPa}$ under saturated conditions and by substitution

$$
\text { [6] } B(\chi)=B+\left(C_{\mathrm{c}}-C_{\mathrm{s}}\right) a(1-\chi)
$$

where $a=\bar{a} / \ln (10)$.

A decrease of parameter $\chi$ induces a shift of the NCL, parallel to the saturated one according to eq. [3] (with $B(\chi)$ from eq. [6]). During a compression phase at constant gravimetric water content the void ratio decreases inducing an increase of 
Fig. 4. Comparison between laboratory data versus the model: $(a)$ water retention curves at three different initial void ratios, $(b)$ compression lines in saturated and unsaturated conditions.
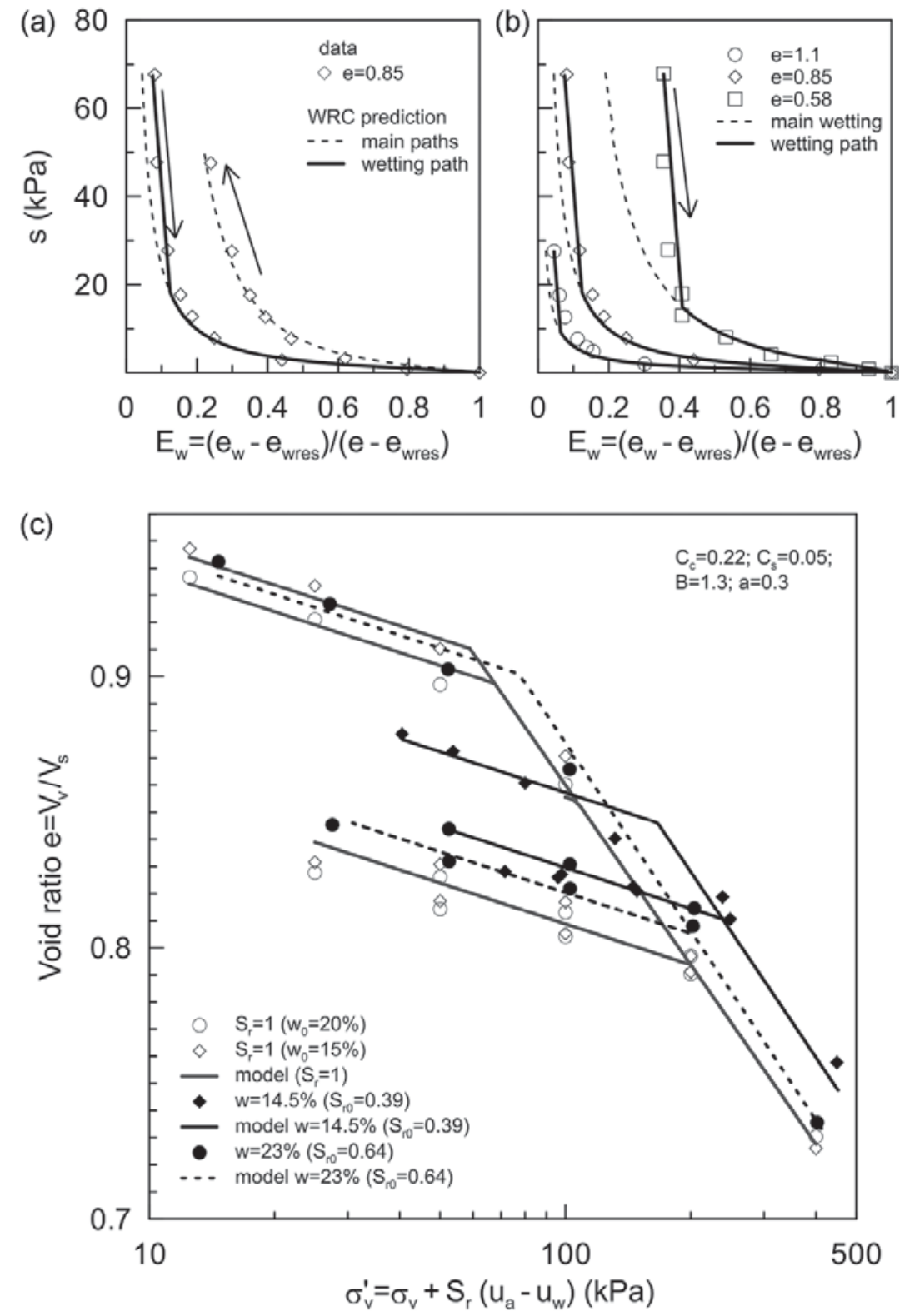

Table 2. Hydraulic model parameters.

\begin{tabular}{lllll}
\hline$n_{0}$ & $P_{0}(\mathrm{kPa})$ & $b$ & $\lambda_{0}$ & $c$ \\
\hline 0.524 & 0.70 & 9 & 0.55 & -2.5 \\
\hline
\end{tabular}

parameter $\chi$ shifting the NCL, which will approach the saturated ones as $\chi$ tends to the unity.

Similar approaches are already proposed by e.g. Al-Badran and Schanz (2010), Zhang and Ikariya (2011), Kukimoto et al. (2011), and recently summarized by Sheng (2011).

The equations proposed by the aforementioned models introduce an additional parameter to capture well the experimental results, while the simple equation proposed here is derived once defined by the yielding law (eq. [2]) and the saturated parameters $C_{\mathrm{c}}, C_{\mathrm{s}}, B$ (eq. [6]).
The constitutive relationship describing the water storage mechanism is defined in terms of a dimensionless water ratio $E_{\mathrm{w}}=E_{\mathrm{w}}(s, n)$, using a modified Van Genuchten equation (Van Genuchten 1980) as follows:

$$
\begin{aligned}
& E_{\mathrm{w}}=\frac{e_{\mathrm{w}}-e_{\mathrm{wres}}}{e-e_{\mathrm{wres}}}=\left\{1+\left[s / P(n)^{1 /[1-\lambda(n)]}\right]\right\}^{-\lambda(n)} ; \\
& P(n)=P_{0} e^{b\left(n_{0}-n\right)} ; \lambda(n)=\lambda_{0} e^{c\left(n_{0}-n\right)} \\
& \dot{E}_{\mathrm{w}}=-k_{\mathrm{s}} \dot{s}
\end{aligned}
$$

where $e_{\mathrm{w}}$ is the water ratio defined as $e_{\mathrm{w}}=V_{\mathrm{w}} / V_{\mathrm{s}}=S_{\mathrm{r}} e, V_{\mathrm{s}}$ is the volume of solids, $e_{\mathrm{wres}}=0.30$ is the residual water ratio, $P$ and $\lambda$ are soil parameters, depending on porosity $n$ via parameters $b$ and $c, k_{\mathrm{s}}$ is the slope of the scanning curves here assumed linear for simplicity. The parameters obtained by interpreting the WRC are reported in Table 2. 
Comparison between the prediction and the laboratory results for the WRC is shown in Figs. $4 a$ and $4 b$. In the range of suction investigated, the model fits the experimental results well over the variation with the void ratio. Figure $4 c$ reports the results of oedometer tests in the plane $e-\log \sigma_{\mathrm{v}}^{\prime}$, where $\sigma_{v}^{\prime}=\sigma_{\mathrm{v}}+S_{\mathrm{r}} \mathrm{s}$, the suction is obtained by inverting the WRC taking into account the hysteresis of water retention curve (eq. [7]) from a known $w=w_{0}(\%)$ and the evolution of the void ratio $e$ during the tests.

The calibration of the parameters obtained by interpreting the oedometric results assuming the parameter $\chi=S_{r}$ are also reported in Fig. $4 c$. The NCL, calibrated on the experimental data, shows a rate of structural degradation tending to the saturated NCL as both the stresses and the degree of saturation increase, which reproduces the experimental behaviour well.

\section{Model prediction}

Considering complete saturation of a soil element from an unsaturated state described by $p, e, S_{\mathrm{r}}, s, \sigma_{\mathrm{v}}$ and hence $\sigma_{\mathrm{vp}}^{\prime}=$ $\sigma_{\mathrm{v}}+S_{\mathrm{r}} s$ (Fig. 3), the deformations are calculated from

$[8]$

$$
\begin{aligned}
& \Delta \varepsilon_{\mathrm{e}}=\frac{C_{s}}{1+e_{0}} \log \left(\frac{\sigma_{\mathrm{vcsats}}^{\prime}}{\sigma_{\mathrm{vp}}^{\prime}}\right) \\
& \Delta \varepsilon_{\mathrm{p}}=\frac{\left(C_{\mathrm{c}}-C_{\mathrm{s}}\right)}{1+e_{0}} \log \left(\frac{\sigma_{\text {vcsats }}^{\prime}}{\sigma_{\text {vcsati }}^{\prime}}\right) \\
& \Delta \varepsilon=\Delta \varepsilon_{\mathrm{e}}+\Delta \varepsilon_{\mathrm{p}}
\end{aligned}
$$

where $\sigma_{\text {vcsati }}^{\prime}$ is the equivalent initial saturated preconsolidation vertical stress and $\sigma_{\text {vcsats }}^{\prime}$ is the saturated preconsolidation vertical stress after saturation and $e_{0}$ the initial void ratio (Fig. 3).

The wetting tests performed in oedometric condition under different vertical load ranging between $100-400 \mathrm{kPa}$. The experimental results are compared with the model prediction in Fig. 5.

Points to the right of the saturated NCL will shrink (collapse) during saturation, while those to the left will swell. It is obvious that the NCLs under unsaturated conditions (eq. [4]) cannot be parallel during compression because the degree of saturation increases and will converge slightly over this range of vertical stresses towards the saturated NCL in the same way as NCLs for natural soils versus reconstituted ones (e.g., Callisto Rampello 2004), which is confirmed by the oedometer test data. The degradation induced by the applied loads is quite well described by the change in degree of saturation and its influence on NCL for this type of soil. The model predicts an overconsolidated state for the point at $\sigma_{\mathrm{v}}=$ $100 \mathrm{kPa}$ with $w_{0}=15 \%$ and a normal consolidated state for the same stress with $w_{0}=20 \%$ before the saturation (Fig. $5 a$ ), both of them shrink during saturation and the final points are quite well predicted by the model. While for the stresses $\sigma_{\mathrm{v}}=$ 200-400 kPa the model predicts a normal consolidated state with $w_{0}=15 \%-20 \%$, respectively (Fig. $5 b-c$ ) before the saturation followed by shrinking during the flooding step. The model predicts quite well the variation of void ratio induced by soaking for samples with $w=20 \%$ and $\sigma_{\mathrm{v}}=200$ $400 \mathrm{kPa}$, respectively, and for sample with $w=15 \%$ with
Fig. 5. Model predictions versus experimental data for one-dimensional compression at $w_{0}=15 \%-20 \%$ for different vertical stress at saturation: $(a) \sigma_{\mathrm{vsat}}=100 \mathrm{kPa} ;(b) \sigma_{\mathrm{vsat}}=200 \mathrm{kPa} ;(c) \sigma_{\mathrm{vsat}}=400 \mathrm{kPa}$.
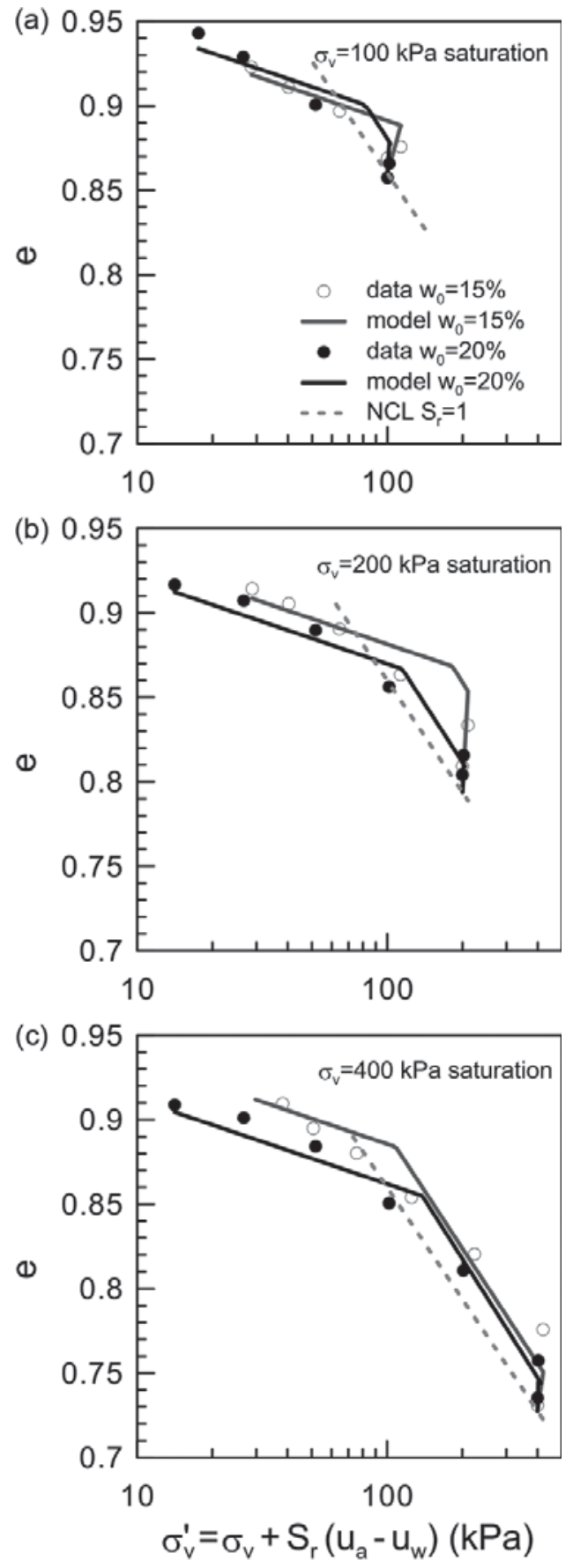

$\sigma_{\mathrm{v}}=100 \mathrm{kPa}$. For the other tests, the model over estimates the variation of void ratio induced by wetting.

\section{Conclusions}

The paper presents a simple model for predicting the deformation induced by wetting of an unsaturated soil (e.g., Rüdlingen silty sand). The preconsolidation vertical stress, predicted by the model, depends on the degree of saturation 
via an exponential law. The dependency of the WRC on the state of the soil was modelled with a modified Van Genuchten equation where fitting parameters depend on porosity and are obtained by interpreting the experimental results at different void ratios. The model predicts the amount of water retained by the soil at different void ratios rather well. The NCL under unsaturated conditions is described by a simple expression that which needs only one more parameter than the saturated NCL and the parameter $\chi$.

The capability of the model to reproduce the behaviour of an unsaturated silty sand has been proved by comparing the experimental results and predictions. The proposed model, despite the simplicity, is able to reproduce the compression induced by saturation at different vertical stress and water content quite well. The model can be used with different definition of the $\chi$ parameter proposed in literature as the effective degree of saturation elevated to an exponent giving satisfactory predictions also for clayey soils.

This model can be useful for several engineering applications, such as predicting settlement of shallow foundations induced by loading and wetting.

\section{Acknowledgements}

The financial support of the European Commission through funding of the "SAFELAND" project and the Competence Centre of Environmental Sustainability through funding of the "TRAMM" project are gratefully acknowledged. The author acknowledges Rebecca Habegger, Erika Merz, and Simone Schneider for their work in the laboratory. The author would like to thank Sarah Springman, Jean Vaunat, and Giulia Viggiani for their valuable comments and contribution. The author acknowledges the two anonymous reviewers for their detailed and helpful comments to the manuscript.

\section{References}

Al-Badran, Y., and Schanz, T. 2010. Yielding surface model of volume change characteristics for unsaturated fine grained soils. In Unsaturated soils. Buzzi, Fityus \& Sheng. [ISBN: 978-0-415-80480-6.]

Alonso, E.E., Gens, A., and Josa, A. 1990. A constitutive model for partially saturated soils. Géotechnique, 40(3): 405-430. doi:10. 1680/geot.1990.40.3.405.

Alonso, E.E., Vaunat, J., and Gens, A. 1999. Modelling the mechanical behaviour of expansive clays. Engineering Geology, 54(1-2): 173-183. doi:10.1016/S0013-7952(99)00079-4.

Alonso, E.E., Pereira, J.M., Vaunat, J., and Olivella, S. 2010. A microstructurally based effective stress for unsaturated soils. Géotechnique, 60(12): 913-925. doi:10.1680/geot.8.P.002.

Askarinejad A., Casini F., Bischof P., Beck A., Springman S.M. 2012. Rainfall induced instabilities: a field experiment on a silty sand slope in northern Switzerland. Rivista Italiana di Geotecnica. [In press.]

Bishop, A.W. 1959. The principle of effective stress. Teknisk Ukeblad, 106(39): 859-863.

Callisto, L., and Rampello, S. 2004. An interpretation of structural degradation for three natural clays. Canadian Geotechnical Journal, 41(3): 392-407. doi:10.1139/t03-099.

Casini, F., Jommi, C., and Springman, S.M. 2010. A laboratory investigation on an undisturbed silty sand from a slope prone to landsliding. Granular Matter, 12(3): 303-316. doi:10.1007/ s10035-010-0182-y.
Casini, F., Vaunat, J., Romero, E., and Desideri, A. 2012. Consequences on water retention properties of double porosity features in a compacted silt. Acta Geotechnica, 7: 1-12. . doi:10. 1007/s11440-012-0159-6.

D’Onza, F., Gallipoli, D., Wheeler, S., Casini, F., Vaunat, J., Khalili, N., et al. 2011. Benchmark of constitutive models for unsaturated soils. Géotechnique, 61(4): 283-302. doi:10.1680/geot.2011.61.4. 283.

Ferber, V., Auriol, J.C., Cui, Y.J., and Magnan, J.P. 2008. Wettinginduced volume changes in compacted silty clays and highplasticity clays. Canadian Geotechnical Journal, 45(2): 252-265. doi:10.1139/T07-081.

Gallipoli, D., Gens, A., Sharma, R., and Vaunat, J. 2003a. An elastoplastic model for unsaturated soil incorporating the effects of suction and degree of saturation on mechanical behaviour. Géotechnique, 53(1): 123-135. doi:10.1680/geot.2003.53.1.123.

Gallipoli, D., Wheeler, S., and Karstunen, M. 2003b. Modelling the variation of degree of saturation in a deformable unsaturated soil. Géotechnique, 53(1): 105-112. doi:10.1680/geot.2003.53.1.105.

Gens, A., Alonso, E.E., and Suriol, J. 1995. Effect of structure on the volumetric behaviour of a compacted soil. In 1st International Conference on Unsaturated Soils, UNSAT1995. Edited by Alonso and Delage. A.A. Balkema, Rotterdam. pp. 83-88.

Gens, A., Sánchez, M., and Sheng, D. 2006. On constitutive modelling of unsaturated soils. Acta Geotechnica, 1(3): 137147. doi:10.1007/s11440-006-0013-9.

Habegger, R., Merz, E., and Schmieder, S. 2011. Settlement induced by wetting: a microstructural investigation. Bachelor thesis, ETHZ, Zurich.

Jommi, C. 2000. Remarks on the constitutive modelling of unsaturated soils. In Experimental Evidence and Theoretical Approaches in Unsaturated Soils. Proceedings of the International Workshop on Unsaturated Soils, Trento. Edited by A. Tarantino and C. Mancuso. Balkema, Rotterdam. pp, 139-153.

Jommi, C., and di Prisco, C. 1994. A simple theoretical approach for modelling the mechanical behaviour of unsaturated soils. In Italian Conference, Il ruolo dei fuidi nei problemi di ingegneria geotecnica, Mondovi. pp. 167-188

Khalili, N., Geiser, F., and Blight, G. 2004. Effective stress in unsaturated soils: review with new evidence. International Journal of Geomechanics, 4(2): 115-126. doi:10.1061/(ASCE)1532-3641 (2004)4:2(115).

Kukimoto, M., Kyokawa, H., Nalai, T., and Shahin, H.M. 2011. A simple elasto-plastic model for unsaturated soils and interpretations of collapse and compaction behaviours. In 5th International Conference on Unsaturated Soils, UNSAT2010, 6-8 September 2010, Barcelona, Spain. pp. 849-855.

Lawton, E.C., Fragaszy, R.J., and Hardcastle, J.H. 1989. Collapse of compacted clavey sand. Journal of Geotechnical Engineering, 115 (9): 1252-1267. doi:10.1061/(ASCE)0733-9410(1989)115:9 (1252).

Lu, N., Godt, J.W., and Wu, D.T. 2010. A closed form equation for effective stress in unsaturated soil. Water Resources Research, 46 (5): W05515 doi:10.1029/2009WR008646.

Mašín, D. 2010. Predicting the dependency of a degree of saturation on void ratio and suction using effective stress principle for unsaturated soils. International Journal for Numerical and Analytical Methods in Geomechanics, 34: 73-90.

Muñoz-Castelblanco, J., Delage, P., Pereira, J.M., and Cui, Y.J. 2011. Some aspects of the compression and collapse behaviour of an unsaturated natural loess. Géotechnique Letters, 1(2): 17-22. doi:10.1680/geolett.11.00003.

Nuth, M., and Laloui, L. 2008. Advances in modelling hysteretic water retention curve in deformable soils. Computers and 
Geotechnics, 35(6): 835-844. doi:10.1016/j.compgeo.2008.08. 001.

Or, D. 1996. Wetting-induced soil structural changes: The theory of liquid phase sintering. Water Resources Research, 32(10): 30413049. doi:10.1029/96WR02279.

Perez-Garcia, N., Houston, S.L., Houston, W.N., and Padilla, J.M. 2008. An oedometer-type Pressure Plate SWCC Apparatus. Geotechnical Testing Journal, 31: 1-9.

Romero, E., and Jommi, C. 2008. An insight into the role of hydraulic history on the volume changes and anisotropic clavey soils. Water Resources Research, 44(12): W12412 doi:10.1029/2007WR006558.

Romero, E., and Vaunat, J. 2000. Retention curves in deformable clays. In Experimental Evidence and Theoretical Approaches in Unsaturated Soils. Proceedings of the International Workshop on Unsaturated Soils, Trento. Edited by A. Tarantino and C. Mancuso. Balkema, Rotterdam. pp. 91-106.

Romero, E., Della Vecchia, G., and Jommi, C. 2011. An insight into the water retention properties of compacted clayey soils. Géotechnique, 61(4): 313-328. doi:10.1680/geot.2011.61.4.313.

Sheng, D. 2011. Review of fundamental principles in modelling unsaturated soil behaviour. Computers and Geotechnics, 38: 757776.

Sheng, D., Fredlund, D.G., and Gens, A. 2008. A new modelling approach for unsaturated soils using independent stress variables. Canadian Geotechnical Journal, 45(4): 511-534. doi:10.1139/T07112.

Springman, S.M., Kienzler, P., Casini, F., and Askarinejad, A. 2009.
Lanslide triggering experiment in a steep forested slope in Switzerland. In Proceedings of the 17th International Conference on Soil Mechanics and Geotechnical Engineeering. Edited by M. Hamza, M.Shaien, and Y. El-Mossallamy. IOS Press. pp. 16981701.

Sun, D.A., Sheng, D., Xiang, L., and Sloan, S.W. 2008. Elastoplastic prediction of hydro-mechanical behaviour of unsaturated soils under undrianed conditions. Computers and Geotechnics, 35(6): 845-852. doi:10.1016/j.compgeo.2008.08.002.

Tamagnini, R. 2004. An extended Cam-clay model for unsaturated soils with hydraulic hysteresis. Géotechnique, 54(3): 223-228. doi:10.1680/geot.2004.54.3.223.

Tarantino, A. 2009. A water retention model for deformable soils. Géotechnique, 59(9): 751-762. doi:10.1680/geot.7.00118.

Van Genuchten, M.T. 1980. A closed-form equation for predicting the hydraulic conductivity of unsaturated soil. Soil Science Society of America Journal, 44(5): 892-898. doi:10.2136/sssaj1980. $03615995004400050002 x$

Vilar, O.M., and Rodrigues, R.A. 2011. Collapse behavior of soil in a Brazilian region affected by a rising water table. Canadian Geotechnical Journal, 48(2): 226-233. doi:10.1139/T10-065.

Wheeler, S., and Sivakumar, V. 1995. An elasto-plastic critical state framework for unsaturated soil. Géotechnique, 45(1): 35-53. doi:10.1680/geot.1995.45.1.35.

Zhang, F., and Ikariya, T. 2011. A new model for unsaturated soil using skeleton stress and degree of saturation as state variables. Soils and Foundations, 51(1): 67-81. doi:10.3208/sandf.51.67. 